\title{
Joint Approach to Sustainability
}

In a joint project, the German Adhesives Association (IVK), German Paint and Printing Ink Association and German Construction Chemicals Association have had sample environmental product declarations (EPDs) created for a selection of products relating to buildings. The official handover of the eight sample documents by the Institute for Construction and the Environment (IBU) to representatives of the three associations took place during the international construction trade fair BAU 2013 in Munich.

C onstruction materials and the way in which they are processed have a major influence on the sustainability of buildings. Detailed information about the individual components of the materials is of fundamental importance in assessing their contribution to sustainability. Environmental product declarations or EPDs, a concept developed primarily by the IBU, fulfil this requirement. EPDs provide comprehensive, neutral information which can be used throughout the world and which includes all the environmental properties of construction products. As a result, they make available the data needed by certification bodies, planners and architects to enable them to evaluate the sustainability of buildings.

Sample EPDs have proved particularly useful in this respect. These are sample declarations drawn up on the basis of framework formulations. They were commissioned by the associations and will be used by their member companies. This was the objective of the joint project set up by the German Adhesives Association (IVK), German Paint and Printing Ink Association and German Construction Chemicals Associa-

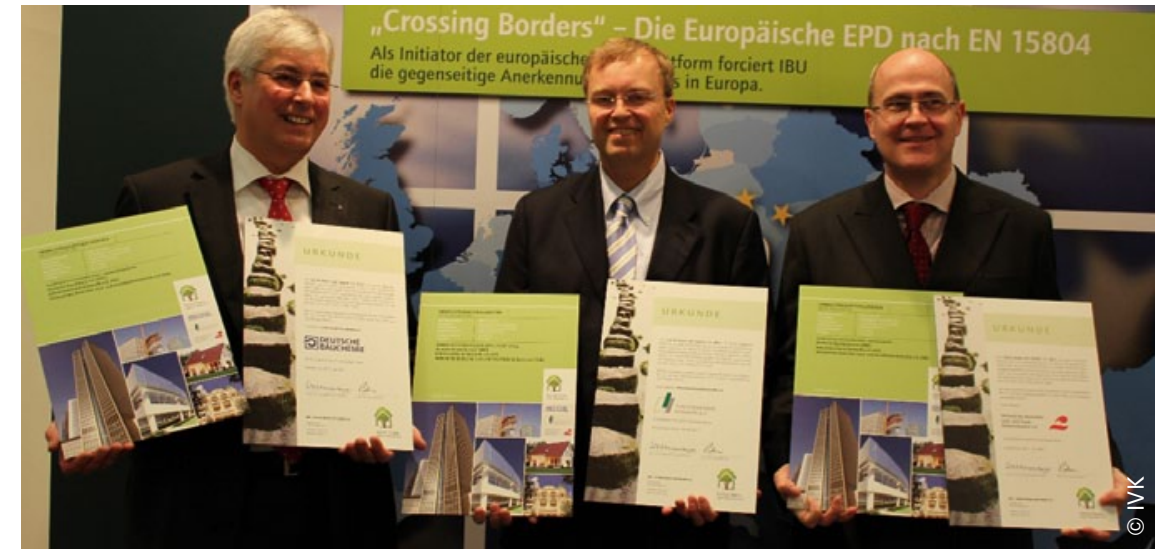

The sample EPDs were handed over to the directors of the three associations involved at the BAU exhibition in Munich: (from left) Norbert Schröter (German Construction Chemicals Association), Klaus Winkels (German Adhesives Association (IVK)) and Michael Bross (German Paint and Printing Ink Association).

tion. They had come to the conclusion that many of the products they were concerned with were very similar and had comparable environmental life cycle assessments. In addition, adhesives, varnishes, paints and other construction chemicals constitute less than 1 percent of the mass of a building. Therefore, from the perspective of the associations it makes little sense to draw up individual EPDs for construction chemicals, adhesives and paints.

\section{TDI Business Acquisition Completed}

B ASF successfully completed its acquisition of parts of Ciech's TDI (toluene diisocyanate) business on 11 March. The TDI production facility of Ciech's subsidiary Zachem, Poland, is not part of the transaction.

"With this acquisition, we are further developing our leading position in the isocyanates market," said Kenneth
Lane, Senior Vice President, Global Strategic Marketing and European Polyurethane Basic Products. "Our highest priority now is focusing on a seamless integration for our customers and our employees." BASF operates TDI plants in Geismar, Louisiana; Yeosu, Korea; Caojing, China; Schwarzheide, Germany; and as of 2014 in Ludwigshafen, Germany.
A total of eight sample EPDs for different groups of products were handed over in January 2013 on the IBU stand at BAU in Munich by IBU director Hans R. Peters to the directors of the three associations. Each EPD contains a series of different text modules describing the various technical applications. To accompany the EPDs, which are available on the Internet, each association has prepared guidelines to help its members categorise their products. 